\title{
The Effect of annealing temperature on corrosion resistance and microstructure of $\mathrm{Zr}-\mathrm{Sn}-\mathrm{Nb}-\mathrm{Fe}$ alloy
}

\author{
G. ZHAO ${ }^{1}$, Zs. TIBA ${ }^{2}$, J. MENYHART ${ }^{3}$ \\ ${ }^{1}$ University of Science and Technology LiaoNing, Liaoning Anshan, 114051, China, Engineering Automation, \\ 821116807@qq.com \\ ${ }^{2}$ University of Debrecen, Faculty of Engineering, Institute of Mechanical and Vehicle Engineering, Department of \\ Air- and Road Vehicles, tiba@eng.unideb.hu \\ ${ }^{3}$ University of Debrecen, Faculty of Engineering, Institute of Mechanical and Vehicle Engineering, Department of \\ Air- and Road Vehicles, jozsef.menyhart@eng.unideb.hu
}

\begin{abstract}
Ti-2Al-2.5Zr titanium alloy plate in beta phase water quench at different times of the reentry after annealing is implemented while primary phase number and size distribution of samples are obtained. This research is carried out on corrosion behavior in 3.5\% [mass fraction] NaCl solution. Experimental study showed that after the beta phase water quenching Ti-2Al-2.5Zr titanium alloyed after $500{ }^{\circ} \mathrm{C}$ annealing when partial recrystallization happened. There seems to be lots of tiny dispersion in the alloy that was annealed with its samples of six-party [HCP] structure of Ti, $\mathrm{Zr}$, Al phase 2 with the dimension below $100 \mathrm{~nm}$. Reaching $500{ }^{\circ} \mathrm{C}$ when the rate of annealing at a primary phase of the sample at $550^{\circ} \mathrm{C}$ is low $90 \%$ of the primary phase is less than $100 \mathrm{~nm}$. The changing of the rule of present decreasing also triggers little difference overall. Precipitation in the process of annealing $\mathrm{Zr}[\mathrm{Nb}, \mathrm{Fe}, \mathrm{Cr}] 2$ is less that proves to be good for corrosion resistance.
\end{abstract}

\section{Introduction}

At present, the research on corrosion resistance of Zr-Sn alloy mainly focuses on the improvement of process technology and the addition of trace elements in alloys. In addition, the optimization of heat treatment process can also improve the corrosion resistance of the alloy [1-3]. There seem to be two main explanations for the mechanism of improving the corrosion resistance of alloys with heat treatment. The first one is that after heat treatment the second phase in alloys changes in quantity, size and distribution. Thus it improves the corrosion resistance. The second one is that a heat treatment process can change the a-Zr namely the content of solid solution alloying elements in [4-6]. Fan Yongjun et al. [7] analyzed the effect of process technology on corrosion resistance of alloy N18 [Zr$1 \mathrm{Sn}-0.35 \mathrm{Nb}-0.3 \mathrm{Fe}-0.1 \mathrm{Cr}$ [mass fraction,\%]. It was found that when the intermediate annealing temperature increased during heat treatment the second phase would coarsen and the corrosion resistance of the alloy would decrease. Cai Jifeng et al. [8] analyzed the relationship between the process technology and the corrosion behavior of $\mathrm{Zr}-1 \mathrm{Nb}-0.01 \mathrm{Cu}$ alloy. The results showed that the smaller the second phase particles in the alloy matrix, the higher the corrosion resistance. 
In this paper the Zr-Sn alloy is treated by water quenching in beta phase. By studying the corrosion behavior of the alloy essential factors influencing the corrosion resistance of the $\mathrm{Zr}-\mathrm{Sn}-\mathrm{Nb}$ alloy during heat treatment can improve better understanding.

\section{Experiment}

A Zr-Sn-Nb-Fe alloy sheet with thickness of $2 \mathrm{~mm}$ was used as a sample in this experiment. The experimental process is as follows: firstly, the alloy sheet was cut into strips and heated up to $980{ }^{\circ} \mathrm{C}$ for 30 minutes, and then it was quenched by water. The solid solution treatment process can be divided into two stages. They are as flows: on one hand holding each sample for 30 minutes at 450 and on the other hand heating up to 470 for 30 minutes, then cooling down for 30 minutes to below 120 for $\mathrm{T} 6$ artificial aging temperature for 46 hours. Then finally water cooling occurs. The cooling rate in the pre-precipitation stage was set to $1^{\circ} \mathrm{C} / \mathrm{min}$ from $470{ }^{\circ} \mathrm{C}$ to $360^{\circ} \mathrm{C}$.

The morphology, size and distribution of primary phase before corrosion of the alloy were observed by JSM_6700 scanning electron microscope. The number and size of primary phase were analyzed by iTEM software and the statistical number of each primary phase was at least 700. The morphology and elemental composition of primary phase of the alloy were analyzed as attachment. JEM-2010 F field emission transmission electron microscopy with INCA energy dispersive spectrometer [EDS] was observed too. Finally, the crystal structure of primary phase was analyzed with selective electron diffraction $[S A D]$.

\section{Analysis of Microstructure Results of Alloys}

The TEM image of Zr-Sn-Nb-Fe alloy obtained in different annealing time is shown in Figure 1. Its figure could indicate that only some parts of the annealed samples has undergone a recrystallization process while a large number of dislocations and recrystallized nuclei have appeared in the incomplete region of the recrystallization process which have not continue to grow. As the incomplete region of recrystallization has had an adverse effect on the image it is difficult to see clearly its beginning. Although a lot of fine primary phases can be wholly seen from the very first signs.

Figure 2 shows EDS, TEM and SAD spectra of primary phase $\mathrm{Zr}$ [Nb, Fe, $\mathrm{Cr}] 2$ in annealed alloy samples. The results indicate that the $\mathrm{Zr}[\mathrm{Nb}, \mathrm{Fe}, \mathrm{Cr}] 2$ phase formed in the alloy sample composes hexagonal structure [HCP], and the crystal particle size is less than $100 \mathrm{~nm}$. In the primary phase of $\mathrm{Zr}$ [Nb, Fe, Cr] 2 annealed at $550 \mathrm{C}, \mathrm{n}[\mathrm{Nb}] / \mathrm{n}[\mathrm{Fe}]$ is about 0.8 . Ti precipitates more sufficiently, and Ti has a faster diffusion rate in alpha-Zr than $\mathrm{Al}$. 


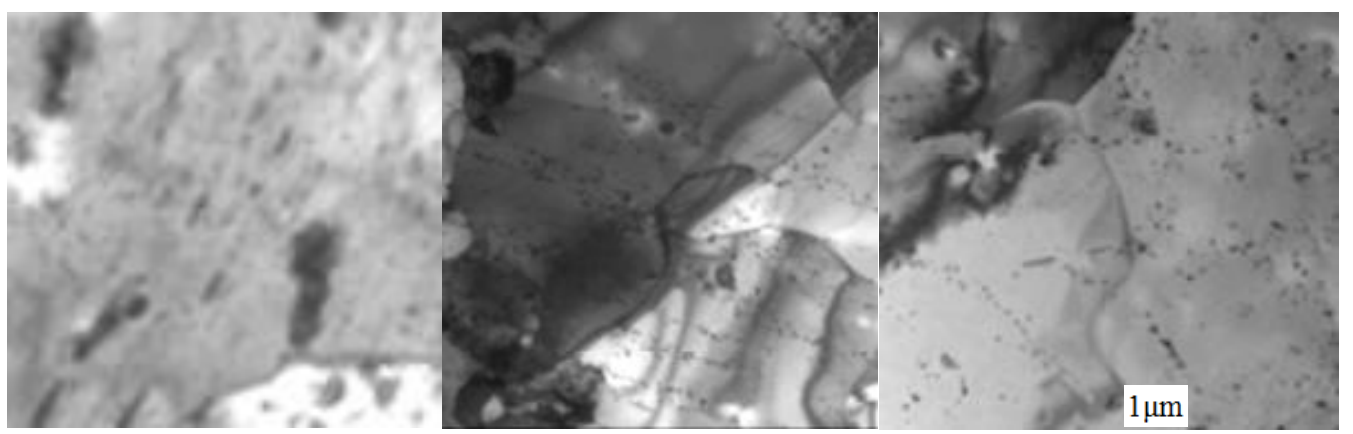

Fig. 1 TEM image of Zr-Sn-Nb-Fe alloy annealed at different temperatures [a] $550^{\circ} \mathrm{C}[\mathrm{b}] 450^{\circ} \mathrm{C}[\mathrm{c}] 550^{\circ} \mathrm{C}$

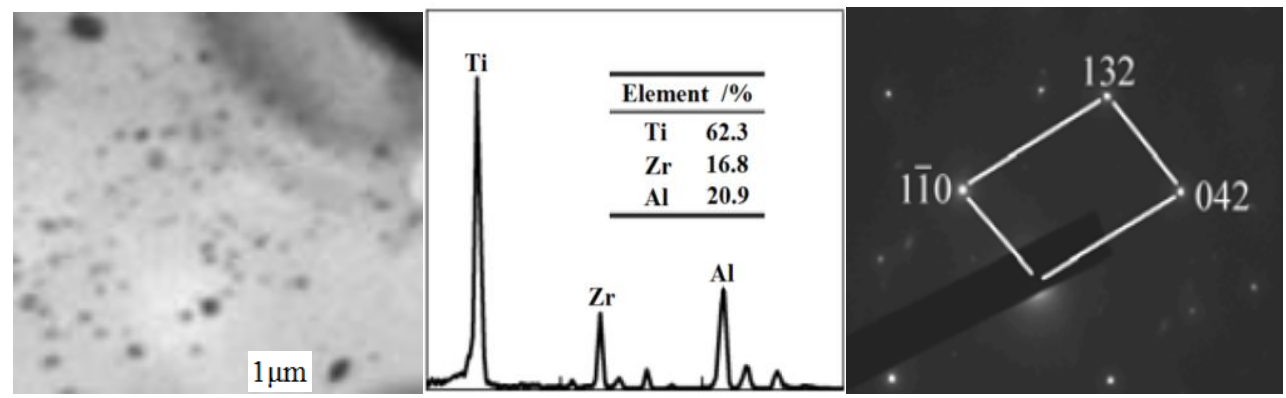

Fig.2 TEM, EDS and SD spectra of typical primary phase $\mathrm{Zr}[\mathrm{Nb}, \mathrm{Fe}, \mathrm{Cr}] 2$ in alloys

The size distribution of primary phase of samples prepared by different annealing processes is displayed in Table 1 . Table 1 depicts that the size of primary phase formed in the samples annealed at $550{ }^{\circ} \mathrm{C}$ is relatively small. The number of primary phases with its size less than $100 \mathrm{~nm}$ accounts for more than $90 \%$ of the total therefore no larger primary phase is formed. The size of primary phase formed in the samples annealed at $500{ }^{\circ} \mathrm{C}$ and $550{ }^{\circ} \mathrm{C}$ is larger, and the maximum is $200 \mathrm{~nm}$. Because of the small number of these primary phases the average size is obviously affected.

\begin{tabular}{|c|c|c|c|c|c|}
\hline Time & $\mathbf{0 - 5 0}$ & $\begin{array}{c}\mathbf{5 0}- \\
\mathbf{1 0 0}\end{array}$ & $\begin{array}{c}\mathbf{1 0 0 -} \\
\mathbf{1 5 0}\end{array}$ & $\begin{array}{c}\mathbf{1 5 0}- \\
\mathbf{2 0 0}\end{array}$ & $>\mathbf{2 0 0}$ \\
\hline $\mathbf{5 5 0}^{\circ} \mathbf{C}$ & 52 & 41 & 2 & 2 & 0 \\
\hline $\mathbf{4 5 0}^{\circ} \mathbf{C}$ & 43 & 52 & 3 & 1 & 0 \\
\hline $\mathbf{5 5 0}^{\circ} \mathbf{C}$ & 38 & 58 & 5 & 4 & 1 \\
\hline
\end{tabular}

Table 1. Size Distribution [nm] of Primary Phase of Samples Prepared at Different Annealing Temperatures

\section{Analysis of Corrosion Performance Results}

Figure 3 shows the SEM results obtained by scanning electron microscopy after alloy corrosion test. From Figure 3, it depicts that after corrosion treatment on the surface of titanium alloy small pitting pits appear and as the increase of corrosion time gradually expands to pitting line the corrosion degree is increasing. 


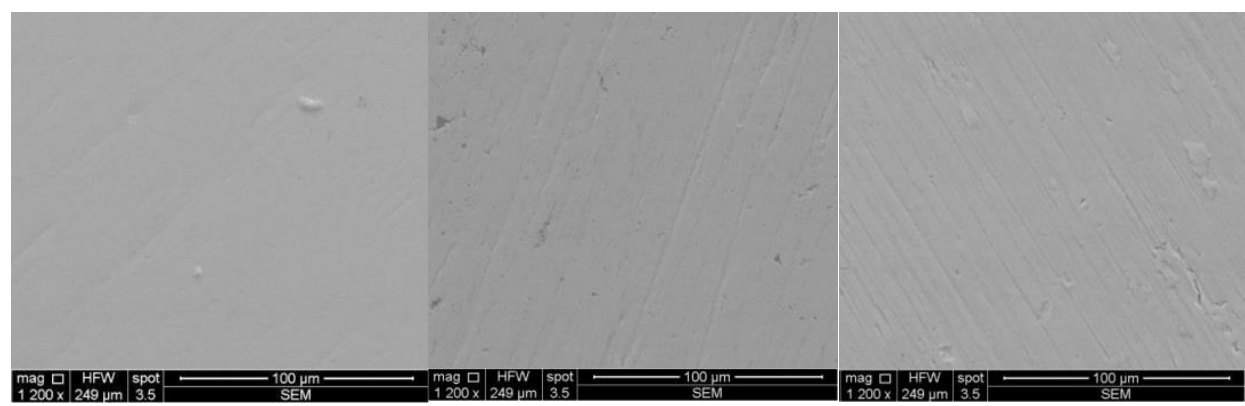

Fig.3 SEM results of corrosion of the alloy after annealing at different temperatures $[a] 550^{\circ} \mathrm{C}[\mathrm{b}] 450^{\circ} \mathrm{C}[\mathrm{c}] 550^{\circ} \mathrm{C}$

Table 2 shows the relationship between corrosion quality and time of samples prepared by various annealing processes after treatment with 3.5\% [mass fraction] $\mathrm{NaCl}$ solution. As the increase of annealing temperature the corrosion quality decreases but the overall difference is not high. It is shown that the corrosion resistance of titanium alloy can be effectively enhanced by reasonable heat treatment. After beta phase water quenching the alloy elements enter into the matrix of a-Zr to form supersaturated solid solution and precipitate into primary phase in subsequent annealing. The samples annealed at $500{ }^{\circ} \mathrm{C}$ are obtained because of the low annealing temperature and the smaller size of $\mathrm{Zr}$ [Nb, Fe, $\mathrm{Cr}] 2$ precipitated phase, which can significantly improve the corrosion resistance of the alloy.

\begin{tabular}{|c|c|c|c|c|}
\hline Time & $\mathbf{1 0 h}$ & $\mathbf{2 4 h}$ & $\mathbf{4 8 h}$ & $\mathbf{9 6 h}$ \\
\hline $\mathbf{5 5 0}^{\circ} \mathbf{C}$ & 58 & 104 & 185 & 387 \\
\hline $\mathbf{4 5 0}^{\circ} \mathbf{C}$ & 55 & 98 & 180 & 377 \\
\hline $\mathbf{5 5 0}^{\circ} \mathbf{C}$ & 53 & 95 & 178 & 372 \\
\hline
\end{tabular}

Table 2. Change of corrosion quality of samples prepared by different annealing processes with exposure time [mg]

Al element can stabilize the beta phase of Ti-Zr binary alloy. Its thermal neutron absorption cross section is very small, only $1.1 \times 10-28 \mathrm{~m} 2$. It can obviously eliminate the negative effect of $\mathrm{C}$ and other impurity elements on the corrosion resistance of Ti-Zr binary alloy and reduces the hydrogen absorption of $\mathrm{Zr}$. The coarse second phase $\mathrm{Zr3Fe}$ in $\mathrm{Zr}-\mathrm{Sn}-\mathrm{Nb}-\mathrm{Fe}$ alloy can cause stress concentration in the alloy and destroy the whole structure of the oxide film. Therefore, when more coarse $\mathrm{Zr} 3 \mathrm{Fe}$ is formed in $\mathrm{Zr}-\mathrm{Sn}-\mathrm{Nb}-\mathrm{Fe}$ alloy its corrosion resistance decreases.

\section{Conclusion}

After annealing at $500^{\circ} \mathrm{C}$, only a part of the $\mathrm{Zr}-\mathrm{Sn}-\mathrm{Nb}-\mathrm{Fe}$ alloy implements recrystallization process. The $\mathrm{Zr}[\mathrm{Nb}, \mathrm{Fe}, \mathrm{Cr}] 2$ phase formed in the alloy sample has hexagonal structure [HCP] and the crystal particle size is less than $100 \mathrm{~nm}$. The size of primary phase in the samples annealed at $550{ }^{\circ} \mathrm{C}$ is small, and $90 \%$ of the primary phase is less than $100 \mathrm{~nm}$.

The corrosion test of Zr-Sn-Nb-Fe alloy after cold deformation was carried out with 3.5\% [mass fraction] $\mathrm{NaCl}$ solution. It was found that the corrosion quality tended to decrease with the increase of annealing temperature, but the overall corrosion quality did not differ much. Small size $\mathrm{Zr}[\mathrm{Nb}, \mathrm{Fe}, \mathrm{Cr}]$ 
International Journal of Engineering and Management Sciences (IJEMS) Vol. 4. (2019). No. 4

DOI: 10.21791/IJEMS.2019.4.48.

2 was precipitated during annealing, which had positive effect on improving the corrosion resistance of the alloy.

\section{References}

[1] Qi.Y.H., Yang.Y.S., Nan.L., Yang.Y.F., Gao.Q., Ti-3Al-2.5V Microstructure and properties of alloy pipe [J]. Special casting and non-ferrous alloy,2011,11:1062-1065.

[2] Cao.S.X., Zhu.D.C., Zhai.W.B., Tu.M.J., Heat treatment for oral use Ti-Zr-[M] Microstructure and wear resistance of multielement alloy [J]. Special casting and non-ferrous alloy,2009,08:760-763+685.

[3] Yue. F., Wu.H.B., Zhao.A.M., Bao.Y.P., Tang.D., Effect of annealing temperature on Precipitation in TiIF steel [J]. Hot working process,2008,22:42-44.

[4] Wang.H.B., Mao.X.N., Hong.Q., Zr-Sn-Nb-FeGeneral annealing process of alloy wire [J]. Hot working process,2009,08:34-37.

[5] You.L., Song.X.P., Effect of rolling and annealing on texture of Ti-18Nb-4Sn alloy [J]. Journal of metals,2008,11:1310-1315.

[6] Gong.M.Q., Zhou.Z.J., Zhang.K., Hu.H.L. Effect of annealing temperature and Ti, Al elements on mechanical properties of 14Cr-ODS alloy [J]. Powder metallurgy material science and Engineering,2015,03:356-361.

[7] Fan.Y.J., Zhou.X.L., He.Z.R., Cao.J.C. ,Cao.Y. ,Chen.J.C., Effect of annealing temperature on transformation, microstructure and tensile properties of Ti-50.8Ni-0.1Zr alloy [J]. Journal of material heat treatment,2013,S1:30-34.

[8] Cai.J.F., He.Z.R., Liu.M.Q., Yang.J., Wang.Q., Effect of annealing process on Microstructure and properties of Ti-Ni-Co shape memory alloy [J]. Journal of material heat treatment,2010,08:20-24 